\title{
MR Imaging of the Brain in Neurologic Wilson Disease
}

\author{
(D) X.-E. Yu, (D)S. Gao, DR.-M. Yang, and (D).-Z. Han
}

\begin{abstract}
S
BACKGROUND AND PURPOSE: Neurologic Wilson disease is an inherited disease characterized by a copper metabolic disorder that causes damage to many organs, especially the brain. Few studies report the relationships between these neurologic symptoms and MR imaging of the brain. Therefore, we investigated the correlation of brain abnormalities in patients with neurologic Wilson disease with their clinical symptoms, age of onset, and lag time to diagnosis.
\end{abstract}

MATERIALS AND METHODS: A cohort of 364 patients was recruited in China between January 2003 and December 2017. Age of onset, lag time until diagnosis, and neurologic symptoms were recorded, and cranial MR imaging was performed. Patients were divided into groups within each of these factors for correlation analysis with the MR imaging brain scans.

RESULTS: Abnormal signals in the MR imaging brain scans were seen in all 364 cases. Affected regions included the putamen, pons, midbrain, and thalamus, while the medulla and occipital lobe were unaffected. The putamen was the most frequently damaged brain region in this study. With the age of onset younger than 10 years, cranial MR imaging scans showed only impairment in the putamen. Patients with a longer lag time before diagnosis were more likely to have impairment in the pons, midbrain, and cortex. Among neurologic symptoms of Wilson disease, torsion spasm is associated with the midbrain and cortex, and choreoathetosis is related to the caudate nucleus.

CONCLUSIONS: Abnormalities in the putamen, pons, midbrain, and thalamus are part of the neuroimaging spectrum of Wilson disease. There is a significant correlation between the site of brain injury and diagnosis lag time.

ABBREVIATION: $W D=$ Wilson disease

W ilson disease (WD), also known as hepatolenticular degeneration, is an autosomal recessive disorder of human copper metabolism, ${ }^{1,2}$ caused by pathogenic variants in the coppertransporting gene $A T P 7 B .^{3-5} \mathrm{WD}$ leads to intracellular copper accumulation, causing damage to many organs, especially the brain. ${ }^{6-8}$ Neurologic WD is one of the main forms of the disease, with some patients showing severe neurologic symptoms that persist despite treatment. Further neurologic deterioration may be observed even after treatment initiation. ${ }^{9-12}$

MR imaging is a sensitive method to evaluate the brains of

Received June 26, 2018; accepted after revision October 30.

From the Department of Pharmacology (Y.X.-E., S.G.), Basic Medical College, Anhui Medical University, Hefei, China; and Hospital of the Institute of Neurology (X.-E.Y., R.-M.Y., Y.-Z.H.), Anhui University of Chinese Medicine, Hefei, China. This work was funded by the Natural Science Foundation of Anhui Province (1508085MH153).

Please address correspondence to Shan Gao, PhD, Department of Pharmacology, Basic Medical College, Anhui Medical University, Hefei 230032, China; e-mail: gaoshan1746@sina.com

-- Indicates open access to non-subscribers at www.ajnr.org

http://dx.doi.org/10.3174/ajnr.A5936 patients with neurologic WD. ${ }^{8,13}$ Whereas abnormalities in the putamen are the most common feature of neurologic $\mathrm{WD},{ }^{14}$ brain shrinkage is also frequently observed. ${ }^{15}$ It has been suggested that the clinical manifestations of WD are region-specific, ${ }^{16}$ and there may be specific differences among patients with WD in China. Therefore, this study aimed to explore the characteristics of cranial MR imaging among patients with WD in China. Many reports have recently published MR imaging data of patients with WD, but the sample sizes of these studies have been limited. ${ }^{17-19}$ Moreover, investigations of the relationship between abnormal findings on MR imaging and neurologic symptoms in patients with WD are sparse. In this study, we conducted MR imaging in 364 patients with WD before they received any treatment for the disease. We provide a detailed report of their MR imaging in conjunction with factors such as age of onset, lag time until diagnosis, and clinical symptoms.

\section{MATERIALS AND METHODS Study Participants}

The study included 364 patients recruited from the Affiliated Hospital of the Institute of Neurology at Anhui University of Chi- 

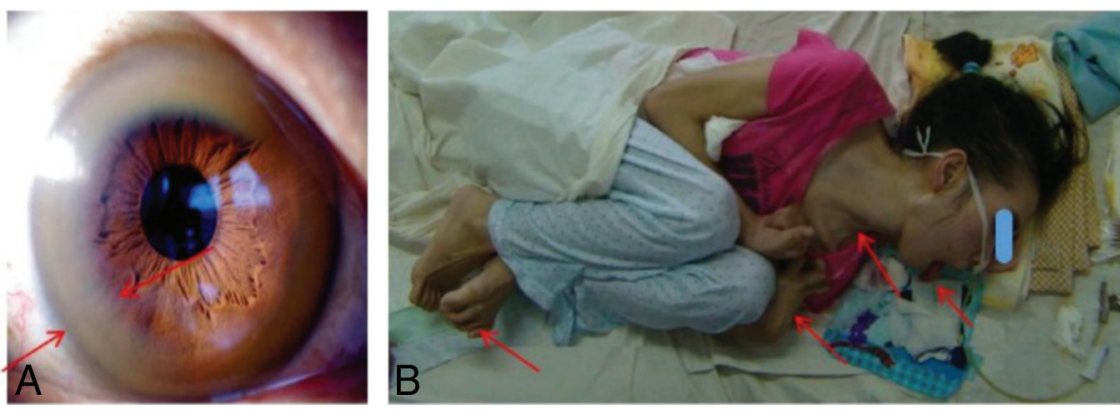

FIG 1. $A$, Kayser-Fleischer rings observable with the unaided eye (arrows). $B$, Wilson disease in a 23-year-old women with torsion spasm (arrows).

nese Medicine between January 2003 and December 2017. Within this cohort, 219 patients were male and 145 were female. All data were collected at the time of the patient's hospitalization, and the data were summarized in a timely manner.

\section{Diagnostic Criteria}

The criteria used for recruitment to this study, as is standard for WD diagnoses, were as follows ${ }^{7,20-22}$ :

1) Family heredity: parental consanguinity, having a sibling with WD, or having a sibling who died from unexplained liver disease.

2) Presence of an extracorticospinal tract symptom such as dystonia, parkinsonism, chorea, torsion spasm, or liver symptoms.

3) Kayser-Fleischer rings visible to the naked eye or with slitlamp examination.

4) Ceruloplasmin level $<2.16 \mu \mathrm{mol} / \mathrm{L}$ or serum copper oxidase level $<0.20$ optical density units.

5) Urinary copper excretion level of $>1.6 \mu \mathrm{mol}$ every 24 hours.

6) Hepatic copper concentration via needle biopsy of $>250 \mu \mathrm{g} / \mathrm{g}$.

Participants fulfilling both criteria 1 and 4 or both criteria 2 and 4 were diagnosed with symptomatic WD. Participants fulfilling both criteria 3 and 5, only criterion 4, or only criterion 6 were diagnosed with asymptomatic WD. Only patients with symptomatic WD were included in the cohort of this study.

\section{Study Measures and Group Analysis}

Age of disease onset, diagnosis lag time (time from symptom onset to definite diagnosis), and type of clinical neurologic symptoms were recorded, and groups were established for subsequent correlation analysis. Patients were divided into 5 groups based on the age of onset, as follows: younger than 10 years, 10-14 years, 15-30 years, 31-40 years, and older than 40 years. In terms of diagnosis lag time, patients were divided into 5 groups: $<3$ months, 4-6 months, 7-12 months, 1-3 years, and $>$ years. Finally, the 5 neurologic symptom groups used for correlation analysis were dystonia, parkinsonism, torsion spasm, and choreoathetosis.

\section{MR Imaging}

A 1.5T MR imaging scanner (Avanto; Siemens, Erlangen, Germany) $(\mathrm{T} 1-\mathrm{TR}=210.0 \mathrm{~ms}, \mathrm{TE}=3.8 \mathrm{~ms}$, time of acquisition $=$ 46.83 seconds, bandwidth $=160.0 \mathrm{~Hz} / \mathrm{Px}, \mathrm{T} 2-\mathrm{TR}=3300.0 \mathrm{~ms}$, $\mathrm{TE}=99.0 \mathrm{~ms}$, time of acquisition $=56.27$ seconds, bandwidth $=$ 195.0 Hz/Px) was used to image the T1 and T2 signals in the basal ganglia, brain stem, and cerebral cortex of participants. The basal

ganglia images included the putamen, caudate, and globus pallidus as well as the thalamus. Images from the brain stem included the midbrain, pons, and medulla. Scans of the cerebral cortex showed the frontal, temporal, parietal, and occipital lobes. All MR images were analyzed separately by 2 researchers (X.Y. and R.Y.). Disagreements about the findings were resolved by discussion until a consensus was reached. This MR imaging protocol was followed for the entire 15-year study period.

\section{Statistical Analyses}

The Kruskal-Wallis test was used to assess the statistical difference in the mean age of onset among the groups. The MR imaging manifestations were used to determine the statistical differences in neurologic symptoms among the groups. Continuous data with a normal distribution are presented as mean $\pm \mathrm{SD}$, and the frequencies of categoric variables are presented as sample size with percentage. All data were analyzed using SPSS, Version 10.01 (IBM, Armonk, New York), and $P<.05$ was considered statistically significant.

\section{RESULTS}

After diagnostic testing, we found that all patients showed ceruloplasmin levels of $<2.16 \mu \mathrm{mol} / \mathrm{L}$, serum copper oxidase levels of $<0.2$ optical density units, and urinary copper excretion levels of $>1.6 \mu \mathrm{mol}$ per 24 hours. All participants were positive on slitlamp examination for Kayser-Fleischer rings (Fig 1A). In addition to the presence of neurologic symptoms, the above-mentioned values resulted in the clear diagnosis of symptomatic WD in all 364 patients included in our study. According to participants' neurologic symptoms, we found 197 cases of dystonia, 127 cases of parkinsonism, 32 cases of torsion spasm, and 8 cases of choreoathetosis (Fig 1B).

All patients underwent cranial MR imaging before their initial copper chelation therapy. The scans showed long T1 and long T2 abnormal signal in the brain (Fig 2A). All 364 patients with WD showed abnormal signal in at least 1 examined brain region (Table 1). Most patients showed abnormal signal in the following brain regions: $81.0 \%$ in the putamen (Fig $2 A$ ), $46.4 \%$ in the pons (Fig $2 B$ ), $36.0 \%$ in the thalamus (Fig 2C), 34.3\% in the caudate nucleus (Fig 2D), 33.5\% in the midbrain (Fig 2E), and $15.4 \%$ in the globus pallidus (Fig $2 F$ ). Brain regions that were less often affected by WD were the temporal lobe (in $3.3 \%$ of patients, Fig $2 G$ ), parietal lobe $(3.3 \%$, Fig $2 H)$, frontal lobe $(3.2 \%$, Fig $2 I)$, cerebellum $(2.2 \%$; Fig $2 J$ ), and corpus callosum (in $2.2 \%$, Fig $2 K$ ). No abnormalities were observed in the occipital lobe (Fig $2 L$ ) or medulla oblongata (Fig 2M).

The most common areas with brain damage in our patients with WD with dystonia were the putamen, pons, and thalamus. However, cranial MR imaging of patients with WD with torsion spasm showed extensive impairment in the putamen, pons, and midbrain. Compared with patients with WD who had other neurologic symptoms, the cerebral cortex was more often impaired in 



FIG 2. WD in a 14-year-old boy with dysarthria and dystonia with abnormal signal in the putamen (A1, A2). WD in a 19-year-old woman with dysphagia and dystonia with abnormal signal in the pons (B1, B2). WD in a 24-year-old woman with dysarthria and parkinsonism with abnormal signal in the thalamus (C1, C2). WD in an 18-year-old man with choreoathetosis with abnormal signal in the caudate nucleus (DI, D2). WD in a 22-year-old woman with dysarthria and parkinsonism with abnormal signal in the midbrain (E1, E2). WD in a 19-year-old woman with dystonia with abnormal signal in the globus pallidus (F1, F2). WD in a 27-year-old man with torsion spasm with abnormal signal in the temporal lobe (G1, G2). WD in a 19-year-old man with epilepsy and dysarthria with abnormal signal in the parietal lobe $(\mathrm{H} 1, \mathrm{H} 2)$. WD in a 17-year-old boy with psychiatric symptoms with abnormal signal in the frontal lobe (17, 12). WD in an 18-year-old man with dysarthria and parkinsonism with abnormal signal in the cerebellum (17,J2). WD in a 13-year-old girl with parkinsonism with abnormal signal in the corpus callosum (K1, K2). WD in a 23-year-old woman with dystonia with normal signal in the medulla oblongata $(L)$. WD in a 27-year-old man with dysarthria and dystonia with normal signal in the occipital lobe (arrows) (M).

Table 1: Correlations between region-specific brain damage in neurologic WD and accompanying neurologic symptoms ${ }^{\mathbf{a}}$

\begin{tabular}{|c|c|c|c|c|c|c|c|c|c|c|c|c|}
\hline $\begin{array}{l}\text { Neurologic } \\
\text { Symptoms }\end{array}$ & $\begin{array}{l}\text { No. of } \\
\text { Cases }\end{array}$ & Putamen & $\begin{array}{l}\text { Globus } \\
\text { Pallidus }\end{array}$ & $\begin{array}{l}\text { Caudate } \\
\text { Nucleus }\end{array}$ & Thalamus & Midbrain & Pons & Cere & $\begin{array}{c}\text { Frontal } \\
\text { Lobe }\end{array}$ & $\begin{array}{c}\text { Temporal } \\
\text { Lobe }\end{array}$ & $\begin{array}{l}\text { Parietal } \\
\text { Lobe }\end{array}$ & $\begin{array}{l}\text { Corpus } \\
\text { Callosum }\end{array}$ \\
\hline Dystonia & 197 & $159(80.7)$ & $34(17.3)$ & $66(33.5)$ & $73(37.1)$ & $67(34.0)$ & $95(48.2)$ & $4(2.0)$ & $4(2.0)$ & $3(1.5)$ & $3(1.5)$ & \\
\hline Parkinsonism & 127 & $104(81.9)$ & 19 (15.0) & 41 & $45(35.4)$ & $31(15.7)$ & $52(26.4)$ & $4(3.1)^{\prime}$ & & $3(2.4)$ & $3(2.4)$ & $6(4.7)$ \\
\hline Torsion spasm & 32 & 25 (78.1) & $2(6.3)$ & $10(31.2)$ & $8(25)$ & $18(56.3)$ & $20(62.5)$ & & $7(21.9)$ & $6(18.8)$ & 6 (18.8) & $2(6.3)$ \\
\hline Choreoathetosis & 8 & $7(87.5)$ & $1(12.5)$ & $8(100)$ & $5(62.5)$ & $6(75)$ & $2(25)$ & & & & & \\
\hline All patients & 364 & $295(81.0)$ & $56(15.4)$ & $125(34.3)$ & $131(36.0)$ & $122(33.5)$ & $169(46.4)$ & $8(2.2)$ & $11(3.2)$ & $12(3.3)$ & $12(3.3)$ & $8(2.2)$ \\
\hline
\end{tabular}

${ }^{a}$ Data are number and percentage.

Table 2: Correlations between age of onset and region-specific brain damage in neurologic WD

\begin{tabular}{|c|c|c|c|c|c|c|c|c|c|c|c|c|}
\hline Age of Onset (yr) & $\begin{array}{l}\text { No. of } \\
\text { Cases }\end{array}$ & Putamen & $\begin{array}{l}\text { Globus } \\
\text { Pallidus }\end{array}$ & $\begin{array}{l}\text { Caudate } \\
\text { Nucleus }\end{array}$ & Thalamus & Midbrain & Pons & Cerebellum & $\begin{array}{c}\text { Frontal } \\
\text { Lobe }\end{array}$ & $\begin{array}{l}\text { Temporal } \\
\text { Lobe }\end{array}$ & $\begin{array}{l}\text { Parietal } \\
\text { Lobe }\end{array}$ & $\begin{array}{l}\text { Corpus } \\
\text { Callosum }\end{array}$ \\
\hline Younger than 10 & 25 & $25(100)$ & & & & & & & & & & \\
\hline $10-14$ & 112 & $107(95.5)$ & & $31(27.7)$ & $47(42.0)$ & $52(46.4)$ & 74 (66.1) & $2(1.8)$ & $3(2.7)$ & $2(1.8)$ & $3(2.7)$ & $8(7.1)$ \\
\hline $15-30$ & 212 & 151 (71.2) & $48(22.6)$ & $88(41.5)$ & $78(36.8)$ & $67(31.6)$ & $81(38.2)$ & $5(2.4)$ & $8(3.8)$ & $9(4.2)$ & $8(3.8)$ & \\
\hline $31-40$ & 14 & $11(78.6)$ & $8(57.1)$ & $5(35.7)$ & $7(50)$ & $3(21.4)$ & $3(21.4)$ & $1(7.1)$ & & $1(7.1)$ & $1(7.1)$ & \\
\hline Older than 40 & 1 & $1(100)$ & & $1(100)$ & $1(100)$ & & 1 & & & & & \\
\hline
\end{tabular}

${ }^{\mathrm{a}}$ Data are number and percentage.

the group with torsion spasm; the probability of damage in $\geq 1$ of the cortical lobes in this group was approximately $18 \%-21 \%$. Taken together, our MR imaging data show that the putamen is the most frequently damaged brain region in patients with $\mathrm{WD}$, regardless of the accompanying neurologic symptoms, followed by the pons and the thalamus. Whereas the symptom of torsion spasm in WD seems to indicate abnormalities in the midbrain and cortex, the symptom of choreoathetosis predominantly suggests damage in the caudate nucleus.

In our patient cohort, age of disease onset varied from 5 to 42 years, with an average onset at $17.04 \pm 6.13$ years of age. Table 2 shows that the age of onset in most patients with WD was younger than 30 years (95.9\% of all patients), among whom $6.9 \%$ were younger than 10 years at disease onset, 30.8\% were 10-14 years of age, and $58.2 \%$ were $15-30$ years of age. In the group with age of onset younger than 10 years, cranial MR imaging scans showed impairment only in the putamen. However, in the group with age of onset of 10-14 years, cranial MR imaging scans very frequently revealed impairment in the brain stem.

The diagnosis lag time, defined as the time between initial symptom onset and confirmed diagnosis, averaged $3.78 \pm 4.46$ years and varied from 1 month to 23 years. Table 3 shows that only 74 patients were diagnosed within 6 months of symptom onset. Our data showed that an increased frequency of the presence of brain damage correlated with an increased delay in treatment initiation. In the group with a lag time of $<3$ months, $90.6 \%$ of participants showed putamen impairment (Fig $2 A$ ) and a few had impaired thalami (Fig 2C) and pontes (Fig 2B). The latter patients had no defects in the midbrain or cerebral cortex. Our research revealed that diagnosis lag time does not correlate with 
Table 3: Correlations between diagnosis lag time and region-specific brain damage in neurologic WD ${ }^{a}$

\begin{tabular}{|c|c|c|c|c|c|c|c|c|c|c|c|c|}
\hline $\begin{array}{l}\text { Time Lag to } \\
\text { Diagnosis }\end{array}$ & $\begin{array}{l}\text { No. of } \\
\text { Cases }\end{array}$ & Putamen & Pallidum & $\begin{array}{l}\text { Caudate } \\
\text { Nucleus }\end{array}$ & Thalamus & Midbrain & Pons & Cerebellum & $\begin{array}{c}\text { Frontal } \\
\text { Lobe }\end{array}$ & $\begin{array}{c}\text { Temporal } \\
\text { Lobe }\end{array}$ & $\begin{array}{c}\text { Parietal } \\
\text { Lobe }\end{array}$ & $\begin{array}{c}\text { Corpus } \\
\text { Callosum }\end{array}$ \\
\hline$\leq 3 \mathrm{mo}$ & 32 & $29(90.6)$ & & $3(9.4)$ & $11(34.4)$ & & $8(25)$ & & & & & $3(9.4)$ \\
\hline 4-6 mo & 42 & 37 (88.1) & $8(19.0)$ & 5 (11.9) & $12(28.6)$ & 9 (21.4) & $10(23.8)$ & & $1(2.4)$ & $2(4.8)$ & $1(2.4)$ & 5 (11.9) \\
\hline 7-12 mo & 76 & $69(90.8)$ & 14 (18.4) & $31(40.8)$ & $17(22.4)$ & $20(26.3)$ & $28(36.8)$ & $2(2.6)$ & $2(2.6)$ & $2(2.6)$ & $1(1.3)$ & \\
\hline $1-3 y r$ & 87 & 69 (79.3) & $5(5.7)^{\prime}$ & $13(14.9)^{\prime}$ & $24(27.6)$ & $19(21.8)$ & $37(42.5)$ & $5(5.7)$ & $5(5.7)$ & $5(5.7)$ & $4(4.6)$ & \\
\hline$>3 \mathrm{yr}$ & 127 & 91 (71.7) & $29(22.8)$ & $73(57.5)$ & $67(52.8)$ & 74 (58.3) & $86(67.7)$ & $1(0.8)$ & $3(2.4)$ & $3(2.4)$ & $6(4.7)$ & \\
\hline
\end{tabular}

${ }^{a}$ Data are number and percentage.


depends on its severity and localization. ${ }^{29}$ According to our findings, dystonia may be related to the putamen, pons, and thalamus.

Similar to dystonia, parkinsonism occurs quite frequently in neurologic WD. Patients with WD show combined presynaptic and postsynaptic nigrostriatal deficits. ${ }^{30}$ In general neurology, tremor treatment varies depending on the tremor type. ${ }^{31,32}$ In our patients, the

FIG 3. High signal intensity lesions on T2WI. Wilson disease in a 14-year-old girl with dystonia, with a diagnosis lag time 5 years (participant group $>3$ years) and abnormal signal in the pons $(D)$, midbrain $(E)$, and frontal and parietal lobes $(F)$ (arrows). unanticipated finding of corpus callosum abnormalities in the group with parkinsonism resulted in corpus callosum repair in some individuals, with

impairment of the putamen in WD but does correlate with the severity of accompanying neurologic symptoms and the likelihood of impairment in the pons (Fig $3 A$ ), midbrain (Fig 3B), and cerebral cortex (Fig 3C). The $P$ value obtained by the Fisher exact probability method was .001 , and the difference was statistically significant. The MR imaging influence in the brain region was related to the course of disease.

\section{DISCUSSION}

Neurologic WD is a genetic disorder that leads to intracellular accumulation of copper in the body, primarily causing damage to the liver and various regions of the brain. Previous studies of MR imaging brain scans in patients with WD have shown abnormal bilateral long T1 and T2 signals in the basal ganglia, especially in the putamen nucleus and head of the caudate nucleus and often in some portion of the thalamus. ${ }^{23}$ Abnormal bilateral long T1 and $\mathrm{T} 2$ signals in the basal ganglia (with or without brain stem impairment) have become one of the important signs of WD. ${ }^{7,23,24}$ Consistent with the literature, our results also showed long T1 and long $\mathrm{T} 2$ abnormal signals in the brain, with the most frequently affected regions including the putamen and caudate nucleus of the basal ganglia (Table 1). The aberrant signal in the basal ganglia is said to be elicited by glial cell hyperplasia as well as edema, necrosis, and lacunae caused by copper deposition. ${ }^{25}$ However, a study by Prayer et $\mathrm{al}^{26}$ showed that some abnormal signals caused by edema and demyelination can disappear after proper de-coppering therapy. The medulla and occipital lobe were entirely spared, with none of our patients with WD showing abnormalities in these regions (Table 1).

Dystonia is among the most debilitating clinical neurologic symptoms commonly observed in neurologic WD. ${ }^{11,27,28}$ In our study, the most common areas of brain damage in patients with WD with dystonia were the putamen, pons, and thalamus. Regardless of etiology, symptomatic treatment of dystonia generally marked improvement of their symptoms. In our study, the most common areas of brain damage in patients with WD with parkinsonism were the putamen, thalamus, and caudate nucleus. Our study findings suggest that parkinsonism may be related to the putamen, thalamus, and caudate nucleus.

Not all of our patients with WD with abnormal caudate nuclei had choreoathetosis. We found that 7 of the 8 patients with WD with choreoathetosis symptoms had an abnormal putamen, and all 8 had an abnormal caudate nucleus. This is basically consistent with the authors' previous research ${ }^{8}$ indicating that the symptom of choreoathetosis strongly correlates with impairment of the caudate nucleus. Thus, the presence of choreoathetosis predominantly suggests damage in the caudate nucleus.

Torsion spasms are a rare neurologic symptom of WD, which contribute to patient disability when present. ${ }^{7} \mathrm{MR}$ imaging data from our patients showed frequent damage to the midbrain and pons but no damage to the remaining regions of the brain stem and medulla oblongata. Taken together, our MR imaging data show that the putamen is the most frequently damaged brain region in patients with $\mathrm{WD}$, regardless of the accompanying neurologic symptoms, followed by the pons and the thalamus.

The data in Table 2 seem to imply that the disease gradually worsens with age before of 30 years of age, but older age of onset is a mitigating factor in $\mathrm{WD}$; however, we cannot ignore the possibility that the lower frequency of brain stem abnormalities and improved prognosis is owing to some other factor that we did not examine in this study, such as disease duration.

The prognosis of WD is closely related to the diagnosis lag time for each patient. ${ }^{33}$ As our correlation analysis showed, the frequency of damage observed in the pons, midbrain, and cortex is directly correlated with the diagnosis lag time. Specifically, the longer the period between symptom onset and confirmed diagnosis, the greater the likelihood that the patient will develop impairment in these brain regions. In the present study, the features 
of WD characterized by torsion spasm included age of onset usually younger than 15 years and diagnosis lag time of at least 2 years (the longest was 23 years). From the trend in the length of diagnosis lag time seen in Table 3, we can speculate that the initial sites of brain injury in neurologic WD are the putamen and thalamus, then developing in the pons and midbrain, and culminating with cortical damage. Therefore, it is crucial for individuals with WD to seek medical care, receive a confirmed diagnosis, and initiate treatment as early as possible.

Differences between our results and those of other MR imaging studies of WD could be due to many reasons: Limited sample sizes, diversity of study participants, variations in the magnetic field strength of the MR imaging scanner used, and duration of therapy all contribute to variations in the results reported in the clinic. The clinical manifestations of WD may be region-specific, ${ }^{16}$ making the demographic composition of the study cohort an important factor for interpretation of the collected data. With 364 patients with WD recruited only from China and MR images collected before the start of any systemic de-coppering therapy, our study has the crucial advantages of a large sample size focused within a single geographic region and being free from the confounding effects of prior treatment.

This study spans a long time, and MR imaging data from gradient-echo images and diffusion images have only become available in recent years. Therefore, most early studies lack these data, and this feature is a drawback of this study.

\section{CONCLUSIONS}

Our study findings showed that the putamen, pons, midbrain, and thalamus are highly prone to damage in neurologic WD, whereas the medulla oblongata and occipital lobe seem completely unaffected. The putamen is the most frequently damaged brain region in this study. In patients with age of onset younger than 10 years, cranial MR imaging scans showed impairment only in the putamen. Patients with a longer lag time before diagnosis were more likely to have impairment in the pons, midbrain, and cortex. Among neurologic symptoms of WD, torsion spasm is associated with the midbrain and cortex, and choreoathetosis is primarily related to the caudate nucleus. The brain abnormalities in patients with neurologic Wilson disease are correlated with their clinical symptoms, age of onset, and lag time to diagnosis.

Disclosures: Xu-En Yu—RELATED: Grant: Natural Science Foundation of Anhui Province, Comments: mitochondrial damage mechanism of mouse brain neurons in Wilson disease model TX (grant No. 1508085MH153). * Shan Gao-RELATED: Grant: Natural Science Foundation of Anhui Province, Comments: mitochondrial damage mechanism of mouse brain neurons in Wilson disease model TX (grant No. 1508085MH153).* Ren-Min Yang-RELATED: Grant: Natural Science Foundation of Anhui Province, Comments: mitochondrial damage mechanism of mouse brain neurons in Wilson disease model TX (grant No. 1508085MH153).* Yong-Zhu HanRELATED: Grant: Natural Science Foundation of Anhui Province, Comments: mitochondrial damage mechanism of mouse brain neurons in Wilson disease model TX (grant No. 1508085MH153).* *Money paid to the institution.

\section{REFERENCES}

1. Bandmann O, Weiss KH, Kaler SG. Wilson's disease and other neurological copper disorders. Lancet Neurol 2015;14:103-13 CrossRef Medline

2. Ferenci P. Pathophysiology and clinical features of Wilson disease. Metab Brain Dis 2004;19:229-39 CrossRef Medline
3. Gromadzka G, Schmidt HH, Genschel J, et al. p.H1069Q mutation in ATP7B and biochemical parameters of copper metabolism and clinical manifestation of Wilson's disease. Mov Disord 2006;21: 245-48 CrossRef Medline

4. Thomas GR, Forbes JR, Roberts EA, et al. The Wilson disease gene: spectrum of mutations and their consequences. Nat Genet 1995;9: 210-17 CrossRef Medline

5. Zong Y, Kong X. Mutation analysis of 35 Wilson's disease pedigrees [in Chinese]. Zhonghua Yi Xue Yi Chuan Xue Za Zhi 2016;33:30-33 CrossRef Medline

6. Schilsky ML. Wilson disease: diagnosis, treatment, and follow-up. Clin Liver Dis 2017;21:755-67 CrossRef Medline

7. Yang RM. Hepatolenticular Degeneration. Beijing: People's Medical Publishing House; 2015

8. Yu XE, Yang RM. 132 cases brain imaging of hepatolenticular degeneration. J Apopl Nerv Dis 2007;1:30-34

9. Litwin T, Dušek P, Czlonkowska A. Symptomatic treatment of neurologic symptoms in Wilson disease. Handb Clin Neurol 2017;142: 211-23 CrossRef Medline

10. Litwin T, Dziez̊yc K, Karliński M, et al. Early neurological worsening in patients with Wilson's disease. J Neurol Sci 2015;355:162-67 CrossRef Medline

11. Lorincz MT. Neurologic Wilson's disease. Ann N Y Acad Sci 2010; 1184:173-87 CrossRef Medline

12. Lucato LT, Otaduy MC, Barbosa ER, et al. Proton MR spectroscopy in Wilson disease: analysis of $\mathbf{3 6}$ cases. AJNR Am J Neuroradiol 2005; 26:1066-71 Medline

13. van Wassenaer-van Hall HN, van den Heuvel AG, Algra A, et al. Wilson disease: findings at MR imaging and CT of the brain with clinical correlation. Radiology 1996;198:531-36 CrossRef Medline

14. Ranjan A, Kalita J, Kumar S, et al. A study of MRI changes in Wilson disease and its correlation with clinical features and outcome. Clin Neurol Neurosurg 2015;138:31-36 CrossRef Medline

15. Kalita J, Naik S, Bhoi SK, et al. Pontomesencephalic atrophy and postural instability in Wilson disease. AJNR Am J Neuroradiol 2017; 38:1343-47 CrossRef Medline

16. $\mathrm{Yu} \mathrm{XE}, \mathrm{Hu} \mathrm{WB}, \mathrm{Han} \mathrm{YZ}$, et al. The regionalism of Wilson disease in Anhui Province. Chin J Nerv Ment Dis 2012;38:435-38

17. Das M, Misra UK, Kalita J. A study of clinical, MRI and multimodality evoked potentials in neurologic Wilson disease. Eur J Neurol 2007;14:498-504 CrossRef Medline

18. Kim S, Song IU, Chung YA, et al. Brain MRI, Tc-99m HMPAO SPECT and F-18 FP-CIT PET/CT findings in a patient with Wilson disease: a case report. Nucl Med Mol Imaging 2014;48:303-05 CrossRef Medline

19. Park HK, Lee JH, Lee MC, et al. Teaching NeuroImages: MRI reversal in Wilson disease with trientine treatment. Neurology 2010;74: e72 CrossRef Medline

20. Chinese Medical Association Neurology Branch. A guide to diagnosis and treatment of hepatolenticular degeneration. Chin J Neurol 2008;41:566-69

21. Roberts EA, Schilsky ML. Diagnosis and treatment of Wilson disease: an update. Hepatology 2008;47:2089-111 CrossRef Medline

22. European Association for Study of Liver. EASL Clinical Practice Guidelines: Wilson's disease. J Hepatol 2012;56:671-85 CrossRef Medline

23. King AD, Walshe JM, Kendall BE, et al. Cranial MR imaging in Wilson's disease. AJR Am J Roentgenol 1996;167:1579-84 CrossRef Medline

24. Thuomas KA, Aquilonius SM, Bergström K, et al. Magnetic resonance imaging of the brain in Wilson's disease. Neuroradiology 1993;35:134-41 CrossRef Medline

25. Scheiber IF, Brůha R, Dušek P. Pathogenesis of Wilson disease. Handb Clin Neurol 2017;142:43-55 CrossRef Medline

26. Prayer L, Wimberger D, Kramer J, et al. Cranial MRI in Wilson's disease. Neuroradiology 1990;32:211-14 CrossRef Medline 
27. Burke JF, Dayalu P, Nan B, et al. Prognostic significance of neurologic examination findings in Wilson disease. Parkinsonism Relat Disord 2011;17:551-56 CrossRef Medline

28. Dusek P, Litwin T, Czlonkowska A. Wilson disease and other neurodegenerations with metal accumulations. Neurol Clin 2015;33: 175-204 CrossRef Medline

29. Thenganatt MA, Jankovic J. Treatment of dystonia. Neurotherapeutics 2014;11:139-52 CrossRef Medline

30. Oder W, Brücke T, Kollegger H, et al. Dopamine D2 receptor bind- ing is reduced in Wilson's disease: correlation of neurological deficits with striatal 123I-iodobenzamide binding. J Neural Transm (Vienna) 1996;103:1093-103 CrossRef Medline

31. Puschmann A, Wszolek ZK. Diagnosis and treatment of common forms of tremor. Semin Neurol 2011;31:65-77 CrossRef Medline

32. Schneider SA, Deuschl G. The treatment of tremor. Neurotherapeutics 2014;11:128-38 CrossRef Medline

33. $\mathrm{Yu} X E, \mathrm{Hu} \mathrm{WB}, \mathrm{Han} \mathrm{YZ}$, et al. The course and prognosis of Wilson's disease. Chin J Neurol 2012;45 